\title{
PENGARUH TERAPI BERMAIN PUZZLE TERHADAP PENGETAHUAN, SIKAP DAN KETERAMPILAN MENCUCI TANGAN PADA ANAK DI SD TAMAN SUKARIA I KOTA TANGERANG
}

\author{
Ema Hikmah \\ Poltekes Kemenkes Banten \\ Korespondensi:ema_hikmah@poltekkesbanten.ac.id
}

\begin{abstract}
Hand washing is very effective in preventing transmission of disease, so encouraging hand washing early is very important so that children are prevented from contracting the disease. Many tools and methods that can be used to improve children's clean and healthy living behavior through health education, one of them are by playing puzzle therapy. This study aims to determine the effect of puzzle playing therapy on knowledge, attitudes and handwashing skills in grade 1 students at SDN Taman Sukaria 1 Tangerang City. Place of research in SDN Taman Sukaria 1 Kota Tangerang from June to November 2018. This study used a quasi-experimental research design. The number of respondents in this study was 59 students with details of 29 control groups and 30 intervention groups. Quasi-experimental design in research using the type of one-group design with pre and post-test. The bivariate analysis used was an independent t-test. Results of the study There were significant differences in puzzle play therapy that could improve the awareness, attitude and handwashing skills of students in Class 1 in SDN Taman Sukaria 1 Kota Tangerang in the intervention group ( $p$-value $=0,000 \alpha=0.05)$. Significant results in this study indicate that this is meaningful if the puzzle play therapy is carried out so students can increase their knowledge, attitudes, and skills in hand washing. Suggested to teachers and parents to create a pleasant atmosphere when learning one of them by using puzzle play therapy.
\end{abstract}

Keywords: Puzzle Therapy, Hand washing

\begin{abstract}
ABSTRAK
Cuci tangan sangat efektif dalam mencegah penularan penyakit, sehingga pengenalan cuci tangan sejak dini sangat penting agar anak tercegah dari terjangkitnya penyakit. Banyak alat dan cara yang dapat digunakan untuk meningkatkan perilaku hidup bersih dan sehat anak melalui pendidikan kesehatan, salah satunya yaitu dengan terapi bermain puzzle Penelitian ini bertujuan untuk mengetahui pengaruh terapi bermain puzzle terhadap pengetahuan, sikap dan keterampilan cuci tangan pada siswa kelas 1 di SDN Taman Sukaria 1 Kota Tangerang. Tempat penelitian di SDN taman Sukaria 1 Kota Tangerang periode Juni sampai Nopember 2018. Penelitian ini menggunakan desain penelitian kuasi-eksperimen. Jumlah responden dalam penelitian ini adalah 59 siswa dengan rincian 29 orang kelompok control dan 30 orang kelompok intervensi. Desain kuasi-eksperimen dalam penelitian menggunakan tipe onegroup design dengan pre dan post test. Analisi bivariat yang digunakan adalah t-test independent. Hasil penelitian Ada perbedaan signifikan terapi bermain puzzle dapat meningkatkan pengetahauan, sikap dan keterampilan mencuci tangan pada siswa SD Kls 1 di SDN Taman Sukaria 1 Kota Tangerang pada kelompok intervens ( $p$ value $=0,000 \alpha=0,05$ ). Hasil yang signifikan pada penelitian ini menunjukan bahwa hal ini bermakna apabila terapi bermain
\end{abstract}


puzzle dilakukan maka siswa dapat meningkat pengetahuan, sikap dan keterampilannya dalam mencuci tangan. Disasankan pada guru dan orangtua agar menciptakan suasana yang menyenangkan pada saat belajar salah satunya dengan menggunakan terapi bermain puzzzle

\section{Kata Kunci: Kata kunci : terapi puzzle, cuci tangan}

\section{PENDAHULUAN}

Indonesia telah melaksanakan berbagai strategi dalam upaya meningkatkan kesehatan. Strategi tersebut lebih menekankan pada upaya promotif dan preventif tanpa mengabaikan kuratif dan rehabilitatif. (Depkes RI, 2009)

Salah satu upaya promotif dan preventif yang telah dicanangkan pemerintah Indonesia adalah dengan melakukan Perilaku Hidup Bersih dan Sehat (PHBS). Salah satu perilaku hidup bersih dan sehat adalah dengan cuci tangan, dimana cuci tangan ini merupakan perilaku hidup sehat yang sangat efektif untuk mencegah penyebaran penyakit. (Riskesdas, 2013). Sebab, salah satu pemicu timbulnya penyakit yakni dari tangan. Untuk itu, mencuci tangan menggunakan sabun merupakan cara terbaik untuk mencegah mikroorganisme penyebab penyakit masuk kedalam mulut, hidung dan anggota tubuh lainnya dengan mudah.

Anak adalah usia yang rentan tertular penyakit. Anak sering kali tidak menghiraukan akan pentingnya cuci tangan, sehingga perlu peran serta orang dewasa ataupun orangtua untuk membiasakan anak berperilaku hidup bersih dan sehat.
Penyakit pada anak dalam beberapa dekade tahun ini semakin berbahaya seperti mulai muncul kembali penyakit diphteri, ISPA, hepatitis A, scabies dan meningkatnya kejadian diare, yang kemungkinan timbul akibat perilaku hygiene perorangan yang tidak baik serta tidak membiasakan cuci tangan dengan sabun. Data organisasi kesejahteraan anak dunia (UNICEF) pada 2013 menyebutkan, setiap tahun lebih dari 1,7 juta kematian anak di bawah umur 5 tahun disebabkan diare dan infeksi saluran pernapasan. Data ini diperkuat temuan WHO yang memaparkan bahwa 760 ribu kasus kematian anak dipicu diare. Tak hanya itu, setiap hari sedikitnya 3 ribu anak di seluruh dunia meninggal karena terjangkit infeksi saluran pernapasan.

Upaya mensosialisasikan perilaku sehat, sanitasi dan mencuci tangan dengan sabun di Nigeria dimulai oleh sebuah program yang diprakarsai oleh UNICEF dengan menggunakan anak sekolah sebagai agen perubahan. Dalam membentuk perilaku sanitasi mandiri dan pengetahuan akan hidup yang bersih dan sehat anak-anak sekolah dirangsang untuk membentuk kelompok- 
kelompok sekolah seperti klub sehat dan hak untuk anak, yang melibatkan orangtua dan mengajak partisipasi komunitas di desa untuk ikut serta dalam proyek-proyek sanitasi. Salah satu sekolah memprakarsai klub lingkungan sehat dimana para murid mempromosikan perilaku mencuci tangan dengan sabun untuk komunitas dan memperkenalkan teknik-teknik untuk menjaga kebersihan serta berusaha agar pengetahuan untuk hidup bersih dan sehat ini diterapkan dirumah. Dua tahun sesudah intervensi ini, perilaku mencuci tangan dengan sabun meningkat hingga 95 persen. Guru melaporkan bahwa para murid datang ke sekolah dalam keadaan bersih, dan kasus cacingan serta penyakit kulit lainnya berkurang. Tidak hanya itu, angka kehadiran murid pun naik dengan teratur per tahunnya. (Kemenkes RI, 2014)

Di Indonesia telah banyak penelitian yang menyatakan terdapat berbagai penyakit dapat di cegah dengan mencuci tangan pakai sabun. Salah satunya adalah diare, ISPA, kecacingan. (Kemenkes RI, 2014)

Berdasarkan pemaparan diatas, cuci tangan sangat efektif dalam mencegah penularan penyakit, sehingga pengenalan cuci tangan sejak dini sangat penting agar anak tercegah dari terjangkitnya penyakit. Banyak alat dan cara yang dapat digunakan untuk meningkatkan perilaku hidup bersih dan sehat anak melalui pendidikan kesehatan. Salah satunya yaitu dengan terapi bermain puzzle sebagai strategi inovasi pengajaran bagi perawat yang memiliki peran sebagai educator dalam memberikan informasi kesehatan kepada anak-anak dengan usia sekolah.

\section{METODE}

Penelitian ini menggunakan desain penelitian kuasi-eksperimen, dengan menggunakan tipe nonequivalent control group design dengan pre dan post test. Intervensi yang diberikan adalah memberikan terapi bermain puzzle pada kelompok perlakuan sedangkan pada kelompok kontrol tidak. Sampel dalam penelitian ini berjumlah 59 siswa yang terdiri dari 30 siswa di kelompok intervensi dan 29 siswa di kelompok kontrol. Kriteria pemilihan dimasukkan dalam penelitian sampai jumlah subyek penelitian terpenuhi.

Analisis data dalam penelitian ini diolah dengan program statistik. Analisis bivariat untuk sampel berpasangan digunakan uji t-test dependen dan untuk data yang tidak berpasangan dilakuakan uji t-tes independen

\section{HASIL}

Hasil penelitian pengaruh terapi bermain puzzle terhadap pengetahuan, sikap dan 
keterampilan mencuci tangan siswa Kls 1 di SDN Taman Sukaria 1 Kota Tangerang. Jumlah responden penelitian sebanyak 59 responden yaitu 29 responden pada kelompok kontrol dan 30 responden pada kelompok intervensi. Analisa Bivariat akan menguraikan ada tidaknya peningkatan pengetahuan, sikap dan keterampilan mencuci tangan sesudah dilakukan terapi bermain menggunakan puzzle, serta apakah ada perbedaan yang bermakna antara sebelum dan sesudah dilakukan terapi bermain terapi puzzle pada siswa kls 1 di SDN taman Sukaia 1 Kota Tangerang pada kelompok intervensi dan kelompok kontrol.

\section{Tabel 1}

Perbandingan Nilai pengetahuan, sikap, keterampilan pada kelompol intervensi sebelum dan sesudah diberikan terapi bermain puzzle

\begin{tabular}{ccccccc}
\hline Variabel & \multicolumn{2}{c}{ Pre-terapi bermain Puzzle } & \multicolumn{2}{c}{ Post-terapi bermain puzzle } \\
& \multicolumn{1}{c}{ Mean } & SD & MinMax & Mean & SD & MinMax \\
\cline { 2 - 7 } & 62,26 & 21,56 & $20-100$ & 84,19 & 11,77 & $60-100$ \\
\hline Pengetahuan & & & & & & \\
\hline Sikap & 25,32 & 2,97 & $16-30$ & 27,00 & 2,69 & $20-30$ \\
\hline Keterampilan & 60,32 & 15,91 & $30-95$ & 89,84 & 12,21 & $60-100$ \\
\hline
\end{tabular}

Tabel 1. menunjukkan bahwa nilai rerata pengetahuan sebelum dilakukan terapi bermain puzzle yaitu 62,26, sesudah dilakukan terapi bermin puzzle reratanya meningkat menjadi 84,19. Nilai sikap sebelum adalah 25,32 sedangkan nilai sikap sesudah dilakukan terapi bermain puzzle adalah 27,00. Nilai rerata keterampilan sebelum adalah 60,32, sesudah dilakukan terapi bermain puzzle terjadi peningkatan yaitu 89,84 .

\section{Tabel 2}

Perbandingan Nilai pengetahuan, sikap, keterampilan pada kelompok control sebelum dan sesudah diberikan terapi bermain puzzle pada kelompok intervensi dan kelompok control

\begin{tabular}{ccccccc}
\hline Variabel & \multicolumn{3}{c}{ Pre } & & Post & \\
\cline { 2 - 7 } & Mean & SD & $\begin{array}{c}\text { Min- } \\
\text { Max }\end{array}$ & Mean & SD & $\begin{array}{c}\text { Min- } \\
\text { Max }\end{array}$ \\
\hline Pengetahuan & 57,59 & 15,27 & $\begin{array}{c}30- \\
90\end{array}$ & 62,26 & 20,77 & $\begin{array}{c}10- \\
100\end{array}$ \\
& & & & & & $17-$ \\
\hline Sikap & 25,21 & 3,33 & $17-$ & 25,45 & 2,97 & 30 \\
& & & 30 & & & $30-$ \\
\hline Keterampilan & 60,86 & 16,04 & $30-$ & 62,76 & 20,07 & 300 \\
\hline
\end{tabular}

Tabel 2. menunjukkan bahwa nilai rerata pengetahuan sebelum adalah 57,59, dan sesudah dilakukan terapi bermain puzzle pada kelompok intervensi 62,26. Nilai sikap sebelum adalah 25,30 sedangkan nilai sikap sesudah dilakukan terapi bermain puzzle pada kelompok intervensi adalah 25,45. Nilai rerata keterampilan sebelum adalah 60,86, sesudah dilakukan terapi bermain puzzle pada kelompok intervensi adalah 62,76.

\section{Tabel 3}

Perbandingan rerata nilai pengetahuan pada kelompok intervensi dan kelompok kontrol sebelum dan sesudah dilakukan terapi bermain puzzle pada kelompok intervensi

\begin{tabular}{lccccc}
\hline Variabel & Klp & Mean & & & $\begin{array}{c}\text { P } \\
\text { value }\end{array}$ \\
\hline Pengetahuan & Intrvensi & & & & \\
& sebelum & 62,26 & 3,87 & 29 & \\
& sesudah & 84,19 & 2,11 & & \\
& Perbedaan & 21,93 & 19,90 & & 0,000 \\
& & & & & \\
& Kontrol & & & & \\
& sebelum & 57,59 & 15,27 & 28 & \\
& sesudah & 63,79 & 20,77 & & \\
& Perbedaan & 6,21 & 2,039 & & 0,045 \\
\hline
\end{tabular}

Ket: *bermakna/signifikan pada $\alpha \leq 0,05$ 
Tabel 3 menunjukkan rata-rata nilai pengetahuan pada siswa kls 1 SD Taman Sukaria sebelum dilakukan terapi bermain puzzle pada kelompok intervensi adalah 62,26 dengan standar deviasi 3,87 dan sesudah dilakukan terapi puzzle adalah 84,19 dengan standar deviasi 2,11. Analisa lebih lanjut adanya perbedaan bermakna antara nilai pengetahuan angka pada kelompok intervensi sebelum dan sesudah dilakukan terapi bermain puzzle dengan kata lain ada perbedaan signifikan bahwa terapi bermain puzzle dapat meningkatkan pengetahuan tentang mencuci tangan yang baik pada siswa SD kls 1 di SDN Taman Sukaria 1 Kota Tangerang pada kelompok intervensi sebesar 21,93 ( $\mathrm{p}$ value $=0,000$ $\alpha=0,05)$.

\section{Tabel 4}

Perbandingan rerata nilai sikap pada kelompok intervensi dan kelompok kontrol sebelum dan sesudah dilakukan terapi bermain puzzle pada kelompok intervensi

\begin{tabular}{llcccc}
\hline Variabel & Klp & Mean & & & P \\
& & & SD & df & value \\
\hline Sikap & Intrvensi & & & & \\
& sebelum & 25,32 & 2,79 & 29 & \\
& sesudah & 27,00 & 2,69 & & \\
& Perbedaan & 1,67 & 2,53 & & 0,001 \\
& & & & & \\
& Kontrol & & & & \\
& sebelum & 25,21 & 3,33 & 28 & \\
& sesudah & 25,45 & 2,97 & & 0,556 \\
\hline
\end{tabular}

Ket: *bermakna/signifikan pada $\alpha \leq 0,05$

Tabel 4. menunjukkan rata-rata sikap pada siswa kls 1 SD Taman Sukaria sebelum dilakukan terapi bermain puzzle pada kelompok intervensi adalah 25,32 dengan standar deviasi 2,79 dan sesudah dilakukan terapi puzzle adalah 27,00 dengan standar deviasi 2,69. Analisa lebih lanjut adanya perbedaan bermakna antara sikap angka pada kelompok intervensi sebelum dan sesudah dilakukan terapi bermain puzzle dengan kata lain ada perbedaan signifikan bahwa terapi bermain puzzle dapat meningkatkan sikap tentang mencuci tangan yang baik pada siswa SD kls 1 di SDN Taman Sukaria 1 Kota Tangerang pada kelompok intervensi sebesar 1,67 ( $p$ value $=0,001 \alpha=0,05)$.

\section{Tabel 5}

Perbandingan rerata nilai keterampilan pada kelompok intervensi dan kelompok kontrol sebelum dan sesudah dilakukan terapi bermain puzzle pada kelompok intervensi

\begin{tabular}{llcccc}
\hline Variabel & Klp & Mean & & $\begin{array}{c}\text { P } \\
\text { value }\end{array}$ \\
\hline Keterampilan & Intrvensi & & SD & df & 0,0000 \\
& sebelum & 60,32 & 15,91 & 29 & \\
& sesudah & 89,84 & 12,21 & & \\
& Perbedaan & 29,94 & 17,43 & & \\
& & & & \\
& Kontrol & & & & \\
& sebelum & 60,86 & 16,04 & 28 & \\
& sesudah & 62,76 & 20,07 & & \\
& Perbedaan & 1,89 & 14,54 & & \\
\hline Ket* * bermakna/signifikan pada $\alpha<0,05$ &
\end{tabular}

Ket: *bermakna/signifikan pada $\alpha \leq 0,05$

Tabel 5. menunjukkan rata-rata nilai keterampilan pada siswa kls 1 SD Taman Sukaria sebelum dilakukan terapi bermain puzzle pada kelompok intervensi adalah 60,32 dengan standar deviasi 15,91 dan sesudah dilakukan terapi puzzle adalah 89,84 dengan standar deviasi 12,21. Analisa lebih lanjut adanya perbedaan 
bermakna antara nilai keterampilan pada kelompok intervensi sebelum dan sesudah dilakukan terapi bermain puzzle dengan kata lain ada perbedaan signifikan bahwa terapi bermain puzzle dapat meningkatkan keterampilan mencuci tangan yang baik pada siswa SD Kls 1 di SDN Taman Sukaria 1 Kota Tangerang pada kelompok intervensi sebesar 29,94 (p value $=0,000$ $\alpha=0,05)$.

\section{Tabel 6}

Perbandingan Rerata Nilai Pengetahuan Antara Kelompok Intervensi dan kelompok control Kelompok Intervensil sesudah dilakukan intervensi

\begin{tabular}{clllll}
\hline Variabel & Mean & SD & SE & & $\begin{array}{c}\text { P } \\
\text { value }\end{array}$ \\
\hline Pengetahuan & & & & & \\
Intervensi & 21,93 & 11,76 & 2,11 & 29 & 0,000 \\
Kontrol & 6,21 & 20,77 & 3,86 & 28 & \\
\hline
\end{tabular}

Tabel 6. Hasil analisis menunjukkan bahwa ada perbedaan yang signifikan selisih rerata antara kelompok intervensi dan kelompok kontrol ( $\mathrm{p}$ value $=0.000$, $\alpha=0,05$ ), pada kedua kelompok terdapat adanya perbedaan yang signifikan, pada kelompok intervensi didapatkan adanya perbedaan yang signifikan meningkatkan pengetahuan sebelum dan sesudah dilakukan terapi bermain puzzle sedangkan pada kelompok kontrol terdapat adanya perbedaan tetapi tidak significant sehingga dapat disimpulkan bahwa terapi bermain puzzle berpengaruh terhadap peningkatan pengetahuan.

\section{Tabel 7}

Perbandingan Rerata Nilai Sikap Antara Kelompok Intervensi dan Kelompok kontrol sesudah dilakukan intervensi

\begin{tabular}{cccccc}
\hline Variabel & Mean & SD & SE & & $\begin{array}{c}\text { P } \\
\text { value }\end{array}$ \\
\hline $\begin{array}{c}\text { Sikap } \\
\text { Intervensi }\end{array}$ & 1,67 & 2,69 & 0,484 & 29 & 0,038 \\
Kontrol & 0,24 & 2,97 & 0,552 & 28 &
\end{tabular}

Tabel 7 Hasil analisis didapatkan bahwa ada perbedaan yang signifikan selisih rerata antara kelompok intervensi dan kelompok kontrol (p value $=0.000$, $\alpha=0,05)$, pada kedua kelompok terdapat adanya perbedaan yang signifikan, pada kelompok intervensi didapatkan adanya perbedaan yang signifikan meningkatkan sikap sebelum dan sesudah dilakukan terapi bermain puzzle sedangkan pada kelompok kontrol terdapat adanya perbedaan tetapi tidak significant sehingga dapat disimpulkan bahwa terapi bermain puzzle berpengaruh terhadap peningkatan sikap.

\section{Tabel 8}

Perbandingan Rerata Nilai Keterampilan Pada siswa SD Antara Kelompok Intervensi dan Kelompok kontrol sesudah dilakukan intervensi di SD Taman Sukaria

\begin{tabular}{cccccc}
\multicolumn{7}{c}{ 1 Kota Tangerang Tahun 2018} & \\
\hline Variabel & Mean & SD & SE & & $\begin{array}{c}\text { P } \\
\text { value }\end{array}$ \\
\hline keterampilan & & & & df & \\
Intervensi & 29,52 & 12,21 & 2,19 & 29 & 0,000 \\
Kontrol & 6,20 & 20,07 & 3,72 & 28 &
\end{tabular}

Ket: *bermakna/signifikan pada $\alpha=0,05$

Tabel 8 hasil analisis menunjukkan bahwa ada perbedaan yang signifikan 
selisih rerata antara kelompok intervensi dan kelompok kontrol ( $\mathrm{p}$ value $=0.000$, $\alpha=0,05$ ), pada kedua kelompok terdapat adanya perbedaan yang signifikan, pada kelompok intervensi didapatkan adanya perbedaan yang signifikan meningkatkan keterampilan sebelum dan sesudah dilakukan terapi bermain puzzle sedangkan pada kelompok kontrol terdapat adanya perbedaan tetapi tidak significant sehingga dapat disimpulkan bahwa terapi bermain puzzle berpengaruh terhadap peningkatan keterampilan.

\section{PEMBAHASAN}

Hasil penelitian menunjukkan bahwa kelompok intervensi berjumlah 30 anak dan kelompok kontrol berjumlah 29 anak. Pada saat pengukuran pengetahuan, sikap dan keterampilan pada kedua kelompok sebelum di lakukan terapi bermain puzzle hasil pretest menunjukkan $\alpha>0,005$ (p value $=0.000, \alpha=0,05)$, hal ini berarti kedua kelompok memiliki kemampuan pengetahuan, sikap dan keterampiln yang sama sebelum dilakukan terapi bermain puzzle.

Pengetahuan pada kelompok control sebelum dilakukan terapi bermain puzzle menunjukkan, 18 orang anak berpengetahuan baik dan 11 orang anak berpengetahuan kurang dengan nilai rerata pengethuan sebelum 57,59. Sedangkan pada kelompok intervensi, terdapat 22 orang anak berpengetahuan baik dan 7 orang berpengetahuan kurang mengenai mencuci tangan dengan enam langkah dengan nilai rerata pengethuan 62,26. Kedua kelompok memiliki lebih banyak yang berpengetahuan baik dibandingkan yang berpengetahuan kurang.

Pada komponen sikap, sebelum dilakukan terapi bermain pada kelompok intervensi menunjukkan pada kelompok control yang mempunyai sikap positif berjumlah 22 orang dan yang mempunyai sikap negative berjumlah 7 orang dengan rerata sikap 25,21. Sedangkan pada kelompok intervensi terdapat 24 anak bersikap positif dan 5 orang anak bersikap negative dengan rerata sikap 25,32. Kedua kelompok memiliki sikap yang positif terhadap mencuci tangan lebih banyak dibandingkan yang bersikap negative.

Komponen keterampilan sebelum dilakukan terapi puzzle pada kelompok intervensi menunjukkan pada kelompok control terdapat 7 orang mempunyai praktek mencuci tangan yang baik dan terdapat 22 orang mempunyai praktek mencuci tangan yang buruk dengan nilai rerata keterampilan 60,86. Sedangkan di kelompok intervensi terdapat 10 orang mempunyai praktek mencuci tangan yang baik, dan terdapat 19 
orang anak mempunyai praktek mencuci tangan yang buruk dengan rerata nialai keterampilan 60,32. Kedua kelompok memiliki keterampilan mencuci tangan yang buruk lebih banyak dibandingkan dengan ketrampilan mencuci tangan yang baik.

Pada komponen pengetahuan dan sikap, baik kelompok control maupun kelompok intervensi memiliki sebagian besar berpengetahuan baik dan bersikap posistif, hal ini dikarenakan di SD Taman Sukaria 1 dan 2 Kota Tangerang secara berkala mendapat kunjungan dari Puskesmas Neglasari. Salah satu kegiatan kunjungan tersebut adalah memberikan penyuluhan tentang mencuci tangan. Pihak sekolah menyatakan bahwa sejak 2 tahun yang lalu fasilitas mencuci tangan sudah tersedia yaitu dengan dibangun wastafel untuk mencuci tangan, wastafel tersebut berjumlah 6 yaitu 3 dilantai bawah dan 3 lagi di lantai atas. Keadaan ini memungkinkan para siswa untuk melakukan kegiatan cuci tangan dengan menggunakan air mengalir. Sedangkan untuk keterampilan mencuci tangan yang benar dengan enam langkah sebagian siswa mengungkapkan bahwa lupa dan tidak ingat langkah-langkahnya karena menurut para siswa yang penting telah melakukan cuci tangan.
Hasil penelitian menunjukkan bahwa nilai rerata pengetahuan sebelum dilakukan terapi bermain puzzle yaitu 62,26, sesudah dilakukan terapi bermin puzzle reratanya meningkat menjadi 84,19 . Analisa lebih lanjut adanya perbedaan bermakna antara nilai pengetahuan angka pada kelompok intervensi sebelum dan sesudah dilakukan terapi bermain puzzle dengan kata lain ada perbedaan signifikan bahwa terapi bermain puzzle dapat meningkatkan pengetahuan tentang mencuci tangan yang baik pada siswa SD kls 1 di SDN Taman Sukaria 1 Kota Tangerang pada kelompok intervensi sebesar 21,93 ( $p$ value $=0,000 \alpha=0,05)$.

Perbedaan rerata anatar kelompok control dan kelompok intervensi menunjukkan rerata peningkatan pengetahuan pada kelompok intervensi adalah 21,93 dengan standar deviasi 11,76 sedangkan pada kelompok kontrol adalah peningkatan sedikit sebesar 6,21 dengan standar deviasi 20,77. Hasil analisis lebih lanjut didapatkan bahwa ada perbedaan yang signifikan selisih rerata antara kelompok intervensi dan kelompok kontrol (p value $=0.000, \alpha=0,05)$, pada kedua kelompok terdapat adanya perbedaan yang signifikan, pada kelompok intervensi didapatkan adanya perbedaan yang signifikan meningkatkan pengetahuan sebelum dan sesudah dilakukan terapi bermain puzzle sedangkan pada kelompok 
kontrol terdapat adanya perbedaan tetapi tidak significant sehingga dapat disimpulkan bahwa terapi bermain puzzle berpengaruh terhadap peningkatan pengetahuan.

Terapi permainan puzzle di berikan pada kelompok intervensi, yaitu dengan memberikan permaianan berupa puzzle dengan gambar enam langkah mencuci tangan. Siswa dibagi dalam kelompok sebanyak 5 kelompok. Peneliti dan asisten peneliti mendampingi siswa pada saat bermain puzzle. Setiap siswa diberikan 1 puzzle dan waktu yang diberikan untuk bermain puzzle selama 30 menit. Pada saat kegiatan bermain puzzle siswa sangat senang dan gembira menyususn puzzlepuzzle tersebut. Ada sebagian siswa dengan mudahnya menyusun puzzle mencuci tangan dan ada sebagian yang lain agak lebih lambat. Hal ini dikarenakan siswa yang lebih cepat menyusn puzzle karena telah terbiasa melakukan permainan tersebut, pada saat TK atau di rumah di sdiakan oleh orangtuanya. Siswa yang terlambat tetap bersemangat menyelesaikan permaian puzzle karena di motivasi oleh teman yang lain yang sudah berhasil menyususn puzzle tersebut.

Pengetahuan anak dapat meningkat setelah diberikan terapi bermain dengan media puzzle dikarenakan anak mendapat berbagai stimulasi, bukan hanya visual tetapi ketrampilan motoric halus dan daya ingat pada anak juga dirangsang, sesuai dengan pengertian pengetahuan menurut Notoatmojo tahun 2012 bahwa pengetahuan merupakan hasil tahu, dan ini terjadi sesudah orang melakukan pengindraan terhadap objek tertentu. Panca indera manusia yaitu indera penglihatan, pendengaran, penciuman, rasa dan raba. Sebagian besar pengetahuan manusia diperoleh melalui mata dan telinga, yaitu proses melihat dan mendengar.

Kegiatan yang dilakukan pada saat bermain puzzle adalah dengan membongkar dan menyusun kembali kepingan puzzle menjadi bentuk utuh. Posisi awal puzzle yang dalam keadaan acak-acakan bahkan keluar dari tempatnya anak akan merasa tertantang untuk karena hal ini yang mendorong kelincahan koordinasi tangan dan pikiran terwujud secara nyata. (Depdiknas, 2003).

Pada saat anak berkonsentrasi untuk menyusun kembali kepingan-kepingan gambar yang sesuai urutan maka aanak akan mendapat tantangan dan timullah rasa keinginan untuk menyelseaikannya. Pada saat anak menyusun puzzle cuci tangan maka dengan otomatis anak akan mengingat langkah demi langkah cara mencuci tangan enam langkah dengan baik dan benar. 
Melakukan permainan dengan media pembelajaran edukatif anak tidak merasa bahwa sedang belajar, sehingga susanan belajar dengan media puzzle sangat menyenangkan bagi anak. Kegiatan yang menyenangkan juga dapat meningkatkan aktifitas sel otak secara aktif, dapat merangsang daya pikir anak, termasuk diantaranya kemampuan konsentrasi dan memecahkan masalah.

Penelitian ini sejalan dengan Penelitian yang dilakukan oleh Nurvita (2014) yang berjudul Permainan Puzzle Berpengaruh Terhadap Kemampuan Kognitif Pada Anak Usia Dini Kelompok B Di TK Pertiwi Karanglor, Manyaran, Wonogiri 2013/2014. mengatakan bahwa secara tidak sadar anak melatih koordinasi mata dan tangan dalam memasang kepingan puzzle menjadi bentuk utuh serta melatih kemampuan kognitif dalam memecahkan masalah dalam permainan tersebut. Anak berkembang lebih optimal sesudah dilakukan eksperimen dengan permainan puzzle. Hal ini mendukung hipotesis yang menyatakan permainan puzzle berpengaruh terhadap perkembangan kognitif anak kelompok B TK Pertiwi Karanglor, Manyaran, Wonogiri 2013/2014.

Hasil penelitian pada komponen sikap menunjukkan rerata peningkatan sikap pada kelompok intervensi adalah 1,67 dengan standar deviasi 2,69 sedangkan pada kelompok kontrol adalah peningkatan sedikit sebesar 0,24 dengan standar deviasi 2,97. Hasil analisis lebih lanjut didapatkan bahwa ada perbedaan yang signifikan selisih rerata antara kelompok intervensi dan kelompok kontrol ( $\mathrm{p}$ value=0.000, $\alpha=0,05$ ), pada kedua kelompok terdapat adanya perbedaan yang signifikan, pada kelompok intervensi didapatkan adanya perbedaan yang signifikan meningkatkan sikap sebelum dan sesudah dilakukan terapi bermain puzzle sedangkan pada kelompok kontrol terdapat adanya perbedaan tetapi tidak significant sehingga dapat disimpulkan bahwa terapi bermain puzzle berpengaruh terhadap peningkatan sikap.

Bermain puzzle adalah permainan yang merupakan kegiatan membongkar dan menyusun kembali kepingan-kepingan satu gambar menjadi bentuk gambar yang utuh. Dengan mengajarkan anak bermain puzzle maka dapat melatih kreativitas, keteraturan dan tingkat konsentrasi pada anak. (Soebachman, 2012). Keuntungan pembelajaran menggunakan media puzzle adalah media puzzle menstimuls anak untuk ikut aktif dalam pembelajaran. Anak yang kurang termotivasi dalam belajar akan termotivasi berperan aktif belajar mencuci tangan dengan media puzzle. Bermain tidak hanya membuat anak menyukai permainan tetapi juga dituntut agar membuat anak untuk teliti dan tekun ketika mengerjakan 
permainan tersebut. Kegiatan yang menyenangkan juga dapat meningkatkan aktifitas sel otak secara aktif.

Menurut Umama tahun 2016 bermain puzzle melatih anak memusatkan pikiran karena ia harus berkonsentrasi ketika merangkai kepingan-kepingan puzzle. Mainan puzzle memberikan berbagai stimulus, seperti: Koordinasi motoric halus, Sensori peraba, Kecerdasan logika matematika, Kecerdasan visual spasial, Konsentrasi,Pembangunan karakter baik kesabaran, kegigihan dan ketelatenan.

Pada Komponen keterampilan menunjukkan rerata peningkatan keterampilan pada kelompok intervensi adalah 29,52 dengan standar deviasi 12,21 sedangkan pada kelompok kontrol adalah peningkatan sedikit sebesar 6,20 dengan standar deviasi 20,07. Hasil analisis lebih lanjut didapatkan bahwa ada perbedaan yang signifikan selisih rerata antara kelompok intervensi dan kelompok kontrol (p value $=0.000, \alpha=0,05), \quad$ pada kedua kelompok terdapat adanya perbedaan yang signifikan, pada kelompok intervensi didapatkan adanya perbedaan yang signifikan meningkatkan keterampilan sebelum dan sesudah dilakukan terapi bermain puzzle sedangkan pada kelompok kontrol terdapat adanya perbedaan tetapi tidak significant sehingga dapat disimpulkan bahwa terapi bermain puzzle berpengaruh terhadap peningkatan keterampilan.

Pada saat bermain puzzle otak anak akan dilatih untuk berpikir kreatif dengan memasang kepingan gambar, ketika tangan memasangan kepingan gambar, keterampilan motoric anak akan semakin terasa, hal ini sejalan dengan pendapat beaty 2013 bahwa bermain puzzle juga mengajarkan anak untuk melatih keterampilan anak, melatih ketangkasan jari, koordinasi mata dan tangan, mengasah otak dan konsep kognitif. (Beaty, 2013)

Semakin terampil anak memasang potongan gambar, keterampilan anak akan semakin baik. Berulang kali anak mencoba memasang dan menggbungkan potongan gambar, anak dapat membuat kesimpulan suatau maslah. Puzzle dapat meningkatkan daya ingat anak karena di dalam puzzleterdapat urutan langkah-langkah mencuci tangan.

Permaianan edukatif sangat disenangi oleh anak, karena belajar lewat permaianan membuat anak tidak menyadari bahwa kegiatan tersebut adalah sedang belajar. Beberapa penelitian membuktikan bahwa rangsangan belajar lewat permaianan dapat meningkatkan kognitif, sikap dan perilaku anak sesuai dengan penelitian yang dilakukan oleh Prayogi (2017) yang 
berjudul yang berjudul Pengaruh Media Video dan Permainan Ular Tangga dalam Peningkatan Perilaku Anak mengenai Cuci Tangan Pakai Sabun (CTPS) di TK Dian Ekawati. Menggunakan rancangan penelitian dan metode yang sama dengan peneliti yakni Non-equivalent control group design, dengan jumlah sampel sebanyak 27 responden, dimana didalam peneltiannya menjelaskan bahwa terdapat perbedaan perilaku anak sebelum dan sesudah diberikan perlakuan pendidikan kesehatan dengan media bermain ular tangga dan lebih berpengaruh dalam peningkatan pengetahuan dan sikap anak mengenai CTPS dibandingkan media video, karena ular tangga lebih banyak memberikan rangsangan terhadap anak dan sesuai dengan keinginan anak yakni bermain.

\section{SIMPULAN}

Terapi bermain puzzle dapat meningkatkan pengetahuan, sikap dan keterampilan anak di SD Taman Sukari 1 Kota Tangerang. Pada kelompok intervensi didapatkan adanya perbedaan yang signifikan meningkatkan pengetahuan, sikap dan keterampilan sebelum dan sesudah dilakukan terapi bermain puzzle sedangkan pada kelompok kontrol tidak ada perbedaan sehingga dapat disimpulkan bahwa terapi bermain puzzle berpengaruh terhadap peningkatan pengetahuan, sikap dan keterampilan mencuci tangan.

\section{DAFTAR RUJUKAN}

Azizah, Nurul. (2015). Pengaruh Terapi Bermain SCL (Snake, Cards and Ladders) terhadap Keterampilan Mencuci Tangan Siswa Kelas I dan II di SDN Pakusasri II Kabupaten Jember. Jakarta: Jurnal Pustaka Kesehatan Volume 3 No. 3

Beaty, Janice J. (2013). Observasi Perkembangan Anak Usia Dini. Kencana Prenademedia Group, Jakarta. Depdiknas. (2003). Undang-Undang RI Nomor 20 Tahun 2003, tentang Sistem Pendidikan Nasional.

Depkes RI. (2009). Sistem Kesehatan Nasional. Jakarta: Depkes RI

Desmita. (2011). Psikologi Perkembangan Peserta Didik. Bandung: Remaja Rosdakarya

Gunarsa, D. S. (2006). Psikologi Praktis: Dari Anak Sampai Usia Lanjut. Jakarta: PT. BPK Gunung Mulia.

Helmi. (2009). 12 Permainan untuk Meningkatkan Intelegensia Anak. Jakarta: Visimedia https://books.google.co.id/books?id=py VUBAAAQBAJ\&pg=PA36\&dq=kons ep+bermain+puzzle\&hl=en\&sa $=X \& v e$ d=0ahUKEwjplJOCt77YAhVFp48KH T5NBPgQ6AEIWDAH\#v=onepage\&q $\underline{\& \mathrm{f}=\text { false }}$ diakses pada 4 Desember 2017

Hidayat, A. Aziz Alimul. (2007). Metode Penelitian Keperawatan dan Teknik Analisis Data. Jakarta: Salemba Medika

Hidayat, Aziz Alimul. (2008). Pengantar Ilmu Kesehatan Anak. Jakarta: Salemba Medika

Kemenkes RI. (2013). Riset Kesehatan Dasar/Riskesdas. Jakarta: Badan Penelitian dan Pengembangan Kesehatan Kementerian Kesehatan Republik Indonesia 
Kemenkes RI. (2014). Infodatin: Perilaku Mencuci Tangan Pakai Sabun di Indonesia. Jakarta: Pusdatin Kemenkes RI

Kementerian Kesehatan RI. (2013). Pedoman Pembinaan Hidup Bersih dan Sehat. Jakarta: Kemenkes RI

Lestari, Titik. (2015). Kumpulan Teori Untuk Kajian Pustaka Penelitian Kesehatan. Yogyakarta: Nuha Medika

Montolalu, dkk. (2009). Bermain dan Permainan Anak. Jakarta: Universitas Terbuka

Notoatmodjo, S. (2012). Metodologi Penelitian Kesehatan. Jakarta: PT. Rineka Cipta

Notoatmodjo, S. (2012). Promosi Kesehatan dan Perilaku Kesehatan. Jakarta: PT. Rineka Cipta

Nurvita. (2014). Permainan Puzzle Berpengaruh Terhadap Perkembangan Kognitif Pada Anak Usia Dini Di TK Pertiwi Karanglor, Manyaran Wonogiri.

Poerwadarmita, W.J.S. (2011). Kamus Umum Bahasa Indonesia Edisi III. Jakarta: Balai Pustaka

Potter, P.A, \& Perry, A.G. (2005) Findamental Nursing: Concept, Process and Practice. Sixth edition. St. Louis: Mosby Year Book.

Prayogi. (2017). Pengaruh Media Video dan Permainan Ular Tangga dalam Peningkatan Perilaku Anak mengenai Cuci Tangan Pakai Sabun (CTPS) di TK Dian Ekawati. Medan: Universitas Sumatera Utara

Proverawati dan Rahmawati. (2012). Perilaku Hidup Bersih dan Sehat (PHBS). Yogyakarta: Nuha Medika.

Proverawati, A \& Rahmawati, E. (2011). Perilaku Hidup Bersih dan Sehat. Yogyakarta: Nuha Medika

Reza, Muhammad. (2013). Meningkatkan Kemampuan Kognitif Melalui Media Puzzle pada Kelompok B di TK Siswa Budi

1

Surabaya. http://ejournal.unesa.ac.id Diakses online pada 4 Desember 2017.

Sobur, Alex. (2016). Psikologi Umum. Bandung: CV. Pustaka Setia

Soebachman, Agustina. 2012. Permainan Asyik Bikin Anak Pintar. Yogyakarta. In Azna Books.

Sugiyono. (2014). Metode Penelitian Kuantitatif Kualitatif dan $R \& D$. Bandung: Penerbit Alfabeta

Sujarweni, V Wiratna. (2015). Statistik untuk Kesehatan. Yogyakarta: Penerbit Gava Media.

Sujiono. (2010). Bermain Kreatif Berbasis Kecerdasan Jamak. Jakarta: PT. Indeks

Sumantri, Arif. (2013). Metode Penelitian Kesehatan. Jakarta: Kencana Prenada Media GroupSunaryo. (2013). Psikologi untuk Keperawatan. Jakarta: EGC.

Supartini. (2004). Konsep Dasar Keperawatan Anak. Jakarta: EGC

Umama. (2016). Pojok Bermain Anak. Yogyakarta: CV. Diandra Primamitra Media

https://books.google.co.id/books?id=fS fTDQAAQBAJ\&pg=PA144\&lpg=PA1 44\&dq=konsep+bermain+puzzle\&sour ce=bl\&ots $=$ mbUdZEHfle \&sig $=$ L1 KdR qLgZdMckSEKhvttcFBrq2A\&hl=en\& sa=X\&ved=0ahUKEwjkz6eNs77YAh

XENY8KHaUBBiIQ6AEIaDAH\#v=on epage\&q=konsep\%20bermain\%20puzz le\&f=false diakses pada 4 Desember 2018

Wawan, A dan Dewi M. (2011). Teori dan Pengukuran Pengetahuan, Sikap dan Perilaku Manusia. Yogyakarta: Nuha Medika

Widhiarso, Wahyu. (2011). SKALO Program Analisis Skala Guttman. Yogyakarta: Fakultas Psikologi UGM

Wong, et al. (2001). Buku Ajar Keperawatan Pediatrik. Jakarta: EGC

World Health Organization. (2009). Guidelines On Hand Hygiene In Health Care. Switzerland: WHO. 
http://who.int/patientsafety/en/ diakses pada 5 Desember 2018

Yulianti, Rani. (2008). Permainan yang Meningkatkan Kecerdasan Anak. Jakarta: Laskar Askara

Rini AT, et al. 2009. Karakteristik Leukemia Limfoblastik Akut pada Anak di Rumah Sakit Kanker Dharmais 2000-2008. http://indonesianjournalofcancer.or.id/e journal/index.php/ijoc/article/view/122. Diakses Oktober 2016

Saadadiyah N, Sartika D. 2015. Hubungan Antara Dukungan Sosial Dengan Character Strength Orang Tua Dari Anak Penderita Kanker Di Rumah Cinta Bandung. http://karyailmiah.unisba.ac.id/index.p hp/psikologi/article/view/1184.

Diakses Oktober 2016 